\title{
STUDY OF PRE-ENGINEERED BUILDING CONCEPT
}

\author{
M D Gawade ${ }^{1}$ and U. P. Waghe ${ }^{2}$ \\ ${ }^{1}$ PG scholar and ${ }^{2}$ Professor, Department of Civil Engineering, \\ Yeshwantrao Chavan College of Engineering, Nagpur
}

\begin{abstract}
A pre-engineered steel building (PEB) has now become one of the most efficient and simplified building type in the steel construction industry. PEB has found a wide application in the Indian civil industry. Use of tapered members for columns and rafters is one of the basic properties of PEB. Use of web-tapered members increases the efficiency of the PEB. Rather there are limitations for design of tapered members by Indian code the use of these members is made in the industry which has its design based on the American design. In this study we have made a review over some literature based over the concept and design of PEB. We have also studied the provisions of the codes and made a brief study on PEB.
\end{abstract}

Key Words : Pre-Engineered Building, web-tapered members

\section{Introduction}

In today's era what a developing country like India need is a fast and rapid progress. And the same is expected from the construction industry. This raised a need of rapid, speedy and efficient construction process, type in both RCC and Steel construction type. Pre-Engineered building is the best way to achieve this. PEB offers you efficiency in cost and time which are the most preferred parameters in construction industry. Compared to the Conventional Steel Building (CSB) the PEB has no any truss system rather it has the column and rafter system. Also PEB has the utilization of web-tapered members, which is not seen in CSB. Web- tapered members are one having the varying depth of web of a member in a definite proportion. This makes the PEB efficient as compared to the CSB. The use of PEB is widely made due to its various advantageous properties. The main drawback is that there are limitations for the design of PEB by use of Indian code. IS 800-2007 has no any provisions made for the use of web-tapered members. So what the PEB organization is they utilize the American code AISC-ASD 9 (Low Rise Metal Buildings Design), AISC 2010 which employs allowable stress design. Generally they make the load calculations based on the Indian code and design based on American code. Various bracing system are also implemented in the PEB.

Typically a PEB is pre-planned building which has no any work to be done on site except making connection. All the members are designed well and a precise detailing is made to obtain an economic structure. According to the design, detailing shop drawings are made. Even every single connection is designed and detailed with accuracy.
The fabrication is carried out according to the drawings. Precision is the key aspect to get the best advantages of PEB. Many PEB organizations aim towards zero percentage loss of material. The PEB also complies of cold-formed members which are utilized as secondary members. Cold-formed members have the advantage of less weight and greater strength which again increases the efficiency of the PEB. For designing of cold-formed members we have IS 301-1975. As everything is ready with each and every detail the time required for the erection of building is very less as compared to CSB. As in CSB you need to make cutting, fabrication on site there is no necessary of such work in PEB.

\section{Review of Literature}

2.1 Muhammad Umair Saleem, Zahid Ahmad Siddiqi, Hisham Qureshi had carried out design of PEB all members i.e. hot rolled sections and cold-formed sections. Minimum weight design of CSB was carried out to achieve the design of the PEB. They state that Minimum Weight is directly proportional to Minimum Cost. These two structures were compared not only economically but also for structural safety. They found that using cold-formed steel for secondary framing instead of hot rolled has decreased the weight by $60 \%$, also by use of built-up sections in place of hot rolled sections for primary framing decreased the cost by $30 \%$. The deflections and sway shown by hot rolled sections when used for primary and secondary framing is less when compared to others. They also stated that, rather built-up sections shows higher sway but is within the limits as specified in MBMA2005. 
2.2 Fahid Aslam, Wasim Abbass, Zahid Ahemed Siddiqi, Raja Rizwan Hussain had carried out the analysis of a frame against the seismic forces. They have carried out comparison between ordinary moment resisting frame and special moment resisting frame. They have found that when there is increase in seismic load the steel required for ordinary moment resisting frame is much higher than special moment resting frame. They also stated that drift is more in ordinary moment frame as compared to special moment resisting frame. They found that steel can be saved by $7 \%$ for main frame and $60 \%$ to $30 \%$ for bracings by use of special moment resting frame.

2.3 G. Sai Kiran, A. Kailasa Rao, R. Pradeep Kumar had made a study over various codes. They have compared various structural parameters between PEB and CSB by using various codes viz IS800:2007, IS800:1984, MBMA-96 and AISC-89. They have found that there is increase in section weight when designed by IS800:1984 as compared to IS800:2007. The deflections stated in Indian standard are higher than MBMA. When the design was compared between IS800:2007 and AISC/MBMA the weight was greater. They also state that the loading provisions made in Indian code are higher than those made in MBMA. They have also stated that IS800:2007 does not consider slender sections which are often used in PEB. They have stated that the crane impact load in vertical direction is same as compared between Indian and American whereas in horizontal direction it is more in MBMA.

2.4 D.Rakesh, V. Sanjay Gokul, G.Amar had carried out a comparison between CSB and PEB. They have obtained the results by analyzing and designing of an Industrial shed. They have found that the total steel takeoff of the PEB is about $60 \%$ as that of CSB. The author have observed that the weight of the frame is dependent on the bay spacing; with increase up to certain limit there is decrease in weight while after that limit it increases. They also found that displacement is more in $\mathrm{CSB}$ as compared to PEB whereas axial force is more in PEB as compared to CSB.

2.5 N. Subramanian had studied over the PEB. He has made a brief description on the selection of framing system. Also he has made a description on the type of materials used for roof and wall. He has stated the types of structure and the types of framing system that can be used. He states that braced frames may be more economical than unbraced frame in situations where the labour cost is low. He has described about one of the roofing system through-fastened lapped-seam roofing. He states that rather this roofing system is more economical it is susceptible to leakage and hence standing-seam metal roofs consisting of metal panel running vertically on the roof deck are used in present day constructions.

\section{Pre Engineered Building}

Per-engineered building is a construction technique which is based on concept of detailed design and detailing before the actual work starts. In this type of structure everything is pre-planned i.e. from designing, detailing of every member to the path of execution which include fabrication, transportation and erection. The main factor that makes PEB less time consuming is the before work design and detailing. Each and every detail is designed, even the connection where the designer provides accurate number of bolts. So the ultimate result of this is that you don't have to waste your time in fabricated on site just as in case of CSB, you just need to make the connections.

Another one difference is the utilization of tapered members. Tapered member sections are based on the moment occurring in the section end. The basic idea implemented is that where there is greater moment the section size is increased and at the other region there is no need to provide the continuous section which is seen in CSB. This makes the section of less weight in PEB.

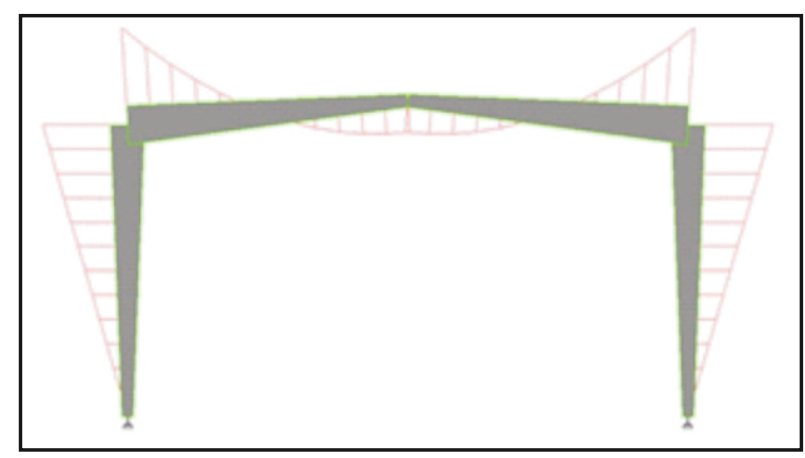

Fig.1 : PEB Frame and Respective area Bending Moment

As we can see in Fig.1 we can provide the greater section depth at the ends where the moment is greater whereas at other end where there is less moment we can reduce the section depth. Due to this the weight of the frame is reduced. The members are fabricated by joining 3 plates of respective thickness. This plates are welded together to form a I-Section. These sections have very less thickness.

\subsection{Components of PEB}

The whole PEB structure can be divided in two main parts:

\section{Primary Member}

These are the primary framing members which are columns and rafters. These are hot-rolled sections and are generally tapered sections.

\section{Secondary Member}

This includes the purlins and girts which can be mostly said as roofing element. These members are generally cold-formed members, which has greater strength as compared to their weight. 
Besides this there are many other components like the sheeting, trims, gutters, and various accessories. Generally all the sheeting and various other components are cold formed rolled which has very less weight and thickness.

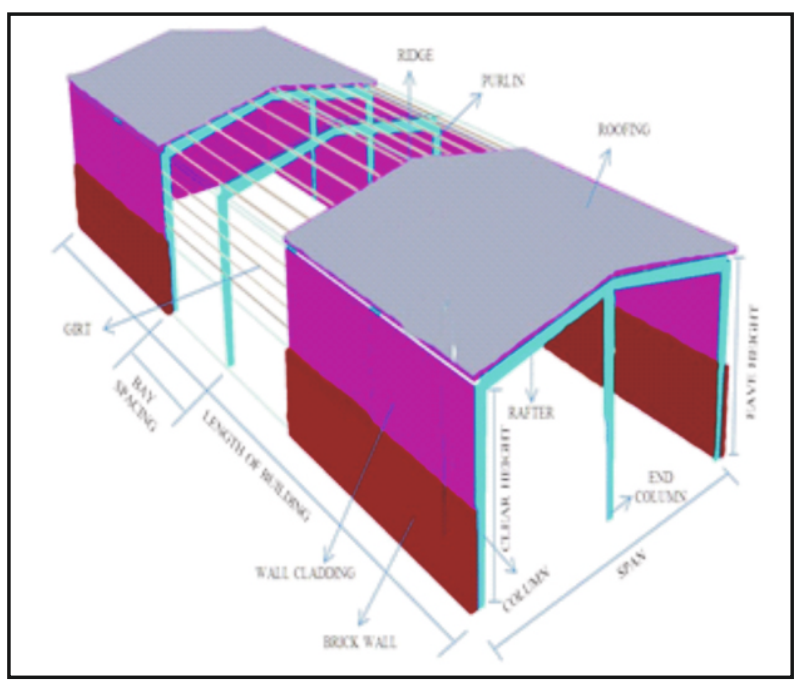

Fig. 2 : Components of PEB

Following are some main parts of the PEB:

1. Column : This is hot rolled section which has minimum yield strength of $345 \mathrm{~N} / \mathrm{mm} 2$. These are generally I Sections which has flange and web plates welded to each other.

2. Rafter : These are the horizontal beam element supporting the roof sheets and purlins. These sections are similar to the column sections but may have different section sizes depending upon the design.

3. Purlin : These are the secondary members running transversely over the rafter. Generally these are coldformed steel sections which may be $\mathrm{Z}$ or $\mathrm{C}$. The minimum yield strength of these members is $340 \mathrm{~N} / \mathrm{mm} 2$.

4. Girts : These are similar to purlin, the only difference is that they are spanned along the columns. They have same properties as that of the purlins.

5. Roofing and Sheeting: These are the sheets to be provided for the roof and the wall. These are roll formed from $0.5 \mathrm{~mm}$ thick cold-rolled steel coated with aluminum/zinc alloy.

6. Trims and Gutters : Trims are pre-formed light gauge metal sheets which are meant to cover the cut steel sections. Similarly are the gutters which are meant for the flow of the roof water.

\subsection{Parameters of PEB}

\section{Geometrical Parameters}

These parameters are related to the geometry of the building i.e. related to the general dimension or say the outline of the plan. The plan of the building is completely dependent upon the demand of the owner. Following are the parameters enlisted below this:

\section{i. Length of Building}

This is related to the longitudinal external dimension of the building. This depends upon the requirement of the owner i.e. what are their requirement in the building decides the size of the building

\section{ii. Span of Building}

This can also be referred as width of the building. This parameter also completely depends upon the requirement of the owner and the external influencing factors like the availability of the land. The span is also related to the configuration of the building.

\section{iii. Bay Spacing}

Bay spacing is the center to center distance between two adjacent frames. It mainly depends upon the length of building. Also the load on the building is an important factor to be considered; if the load is very high then the bay spacing should be reduced as far as possible. In general standards the bay spacing must be approx. $6 \mathrm{~m}$, $7.5 \mathrm{~m}$ and $9 \mathrm{~m}$

\section{iv. Set Back}

It is the distance of building front face or the frontal edge of the building to the boundary line of the plot. It is decided on the regulations of Building By-Laws. This should be followed to keep minimum distance else the maximum can be according to the type of industry and the choice of the owner.

\section{v. Floor Finish Level (FFL)}

This level is decided by the engineer. Generally it is taken as low as possible, but if there are chances of the flood then it is accordingly increased by the designer. The owner can also demand for some floor height. But the designer should decide the filling to be made and the thickness to be provided depending on the functionality of the building.

\section{vi. Clear Height}

It is the distance between FFL to the lowest inside point of rafter or it can be said as the connection bottom line. It is decided by the owner or basically is dependent on the operations that are to be carried out in the building. While deciding the clear height all the factors must be considered the size of gantry must be verified and then the clear height must be finalized.

\section{vii. Eave Height}

It is the distance from bottom of column i.e. base plate to the eave strut. The standard eave height varies from $3 \mathrm{~m}$ to $8 \mathrm{~m}$. But again it is dependent on the clear height. Eave height is also decided by the designer to get efficient structure against loading. 


\section{viii. Slope of Roof}

This too up to some extent depends on the owner demand. But the designer must use a proper proportion as this is governing factor for the application of the wind load.

\section{Designing Parameters}

Designing parameters include various factors like section size, material properties, and also many factors. These parameters are mainly dependent to the loading over the structure and the availability of sections. Following are the design parameters

\section{i. Loads}

This includes all the loads acting on the structure and also the load combinations according to the respective codes.

\section{ii. Section dimension}

This includes the depth of the web, width of the flange, thickness of both flange and web. This should be designed precisely such that the section is of minimum weight where satisfying the loading condition. This also includes the design of the secondary members. They must be designed well for the wind load.

\section{iii. Effective length}

This is the length of the members which is to be considered during the design of member. This depends on the end conditions of the member whether it is fixed or pinned.

\section{iv. Bracing}

This is one of the most important factors which govern the stability of the structure against lateral load. The designer must properly design the bracing members and system.

\section{Detailing Parameter}

These include the details about each and every connection and detailing about every single member of object used in the building. This includes making detailing like:
i. Anchor Bolt Plan
ii. Roof Framing and Sheeting Plan
iii. Ridge Frame Cross Section
iv. Endwall Framing and Sheeting Elevation
v. Sidewall Framing and Sheeting Elevation

\subsection{Advantages and Disadvantages of PEB}

The advantage of PEB over the CSB type is that it saves time and money. The main factor the PEB saves the cost and time for overall project which is due to its accurate design and detailing. Another advantage is that rather of less weight PEB is more efficient for lateral loading may be due to wind or earthquake. The PEB has best advantage of flexibility; which means we can utilize all the members again and again for different structural configuration as all the connections are made by bolts. This is not possible in $\mathrm{CSB}$ as there are welded connections. PEB can provide better aesthetical and fictional outcomes as compared to the CSB.

The disadvantage in PEB is that it lacks in reserve strength. A PEB is designed to bear load to its fullest extent which means there is no any scope for excessive loading.

\section{Conclusion}

PEB is an effective construction option as compared to CSB when it comes to steel structures. There are many choices that can be made in structural configuration of PEB. From previous research work it is clear that the weight of PEB is very less as compared to CSB where both has same load bearing capacity. PEB requires very accurate design and detailing unlike CSB.

\section{References}

[1] Muhammad Umair Saleem, Zahid Ahmad Siddiqi, Hisham Qureshi, " Minimum Weight Design of Pre-Engineered Steel Structures using Built-up Sections and Cold Formed Sections," Advanced Materials Research Vol.684, pp 125-129, 2013

[2] Fahid Aslam, Wasim Abbass, Zahid Ahemed Siddiqi, Raja Rizwan Hussain, "Economical Structural Performance of Steel Moment Resting Building Frames Using the Section Variation Technique," Journal of Construction, April 2014

[3] G. Sai Kiran, A. Kailasa Rao, R. Pradeep Kumar, "Comparison of Design Procedures for PreEngineering Buildings (PEB): A Case Study," World Academy of Science, Engineering and Technology, International Journal of Civil, Architectural, Structural and Construction Engineering Vol.8, No.4, August 2014

[4] D.Rakesh, V. Sanjay Gokul, G.Amar, "Design and Analysis of Conventional and Pre-Engineered Building (R.C.C and Steel)," International Journal of Engineering Development and Research, Vol.4, Issue 2, 2016

[5] N. Subramanian, "Pre-Engineered Buildings Selection of Framing System, Roofing \& Wall Materials," The Masterbuilder, July 2008 